\title{
Non-arteritic anterior ischemic optic neuropathy secondary to acute primary-angle closure
}

This article was published in the following Dove Press journal:

Clinical Ophthalmology

4 July 2013

Number of times this article has been viewed

\section{Ajay E Kuriyan \\ Byron L Lam}

Bascom Palmer Eye Institute, University of Miami, Miami, FL, USA

Correspondence: Ajay E Kuriyan Bascom Palmer Eye Institute, University of Miami, 900 NW 17th Street, Miami, FL, 33|36, USA

$\mathrm{Tel}+\mathrm{I} 3053266000$

Email akuriyan@med.miami.edu
Purpose: To describe a case of non-arteritic ischemic optic neuropathy (NAION) secondary to acute primary-angle closure (APAC).

Methods: Case report.

Results: A 50-year-old woman with painful visual loss in the right eye was found to be in APAC with a right afferent pupillary defect. Laser peripheral iridotomy relieved pain but did not improve vision. Diffuse optic disc edema in the right eye and a small cup-to-disc ratio in the left eye were evident. Magnetic resonance imaging was normal. The patient was diagnosed with non-arteritic ischemic optic neuropathy (NAION) secondary to APAC, a rare clinical entity which can result in markedly decreased visual acuity.

Conclusion: NAION secondary to APAC is a rare clinical entity that can result in severe vision loss.

Keywords: acute angle closure glaucoma, perfusion pressure, NAION, optic nerve

\section{Introduction}

The prevalence of acute primary-angle closure (APAC) is 0.04 to 0.6 per thousand in the United States in patients older than $40 .^{1,2}$ The incidence of non-arteritic ischemic optic neuropathy (NAION) is two to ten per 100,000 in the population older than $50 . .^{3,4}$ NAION secondary to APAC was described by Sonty and Schwartz in 1981. ${ }^{5}$ There have been four subsequent case reports (five eyes) describing NAION secondary to APAC. ${ }^{6-9}$ Patients present with typical APAC symptoms and signs, which include pain, headache, nausea and vomiting, conjunctival injection, corneal edema, elevated intraocular pressure (IOP), closed angles, and a shallow anterior chamber. NAION was present at the time of presentation for APAC in four of six eyes and developed one week after APAC in two eyes. ${ }^{5-9}$

\section{Case report}

A 50-year-old woman with a history of hypertension and dyslipidemia presented with redness, pain, decreased vision, headache, and nausea, for approximately 10 hours. She reported no similar prior episodes. The patient was taking metoprolol, $50 \mathrm{mg}$, at bedtime; hydrochlorothiazide, $25 \mathrm{mg}$, daily; amlodipine, $25 \mathrm{mg}$, daily; lisinopril, $20 \mathrm{mg}$, daily for hypertension; simvastatin, $40 \mathrm{mg}$, at bedtime for dyslipidemia; and aspirin, $81 \mathrm{mg}$, daily for cardiovascular risk factors.

Best-corrected visual acuity (VA) was hand motion at 4 feet right eye and 20/20 left eye (manifest refraction: plano $+0.75 \times 135$ ). Her pupil was $5 \mathrm{~mm}$ in the right eye and $4 \mathrm{~mm}$ in the left, and she was noted to have a moderate relative afferent 
pupillary defect (RAPD) in the right eye. Her IOP were $41 \mathrm{mmHg}$ right eye and $15 \mathrm{mmHg}$ left eye. The right eye had moderately severe ciliary injection, corneal edema, a shallow anterior chamber (closed peripherally, 1/2 corneal thickness centrally), and a moderate nuclear sclerotic cataract. There was no posterior synechiae, and her pupil was minimally reactive. The left eye was quiet, had a shallow anterior segment ( $1 / 4$ corneal thickness peripherally, $1 / 2$ corneal thickness centrally), and a mild nuclear sclerotic cataract. The view of the posterior segment in the right eye was obscured by the corneal edema. The left optic nerve head appeared normal with a cup-to-disc ratio of 0.1 . Gonioscopy demonstrated that her angle was closed $360^{\circ}$ in the right eye and was Shaffer Grade II (anterior trabecular meshwork) $360^{\circ}$ in the left.

The patient was treated for APAC in the right eye with timolol, dorzolamide, and brimonidine drops every 30 minutes and acetazolamide $500 \mathrm{mg}$ orally. One hour later, the IOP was $34 \mathrm{mmHg}$ and she was still experiencing severe pain and decreased vision. After instillation of pilocarpine $2 \%$, a laser peripheral iridotomy (LPI) was performed in the right eye without complications and the anterior chamber deepened, the IOP decreased to $14 \mathrm{mmHg}$, and the patient felt a marked improvement in pain. However, she reported that her vision did not improve. Due to the right RAPD, the patient was asked to return the following morning for a dilated fundus exam.

Upon the patient's return, she reported no pain in her right eye but noted no change in vision. VA remained at hand motion at 4 feet with a moderate RAPD and an IOP of $12 \mathrm{mmHg}$. Her conjunctival injection and corneal edema had resolved. Her LPI was patent, and her anterior chamber was shallow ( $1 / 4$ corneal thickness peripherally), but significantly deeper than the previous day. Gonioscopy demonstrated her angle was Shaffer Grade II $360^{\circ}$ without peripheral anterior synechiae. The right optic nerve head had $360^{\circ}$ edema and an area of subretinal fluid extending into the nasal aspect of macula from the optic disc temporally (Figure 1A). The examination of the left eye was unchanged (Figure 1B). Optical coherence tomography (OCT) demonstrated optic nerve edema and subretinal fluid extending to the macula in the right eye (Figure $2 \mathrm{~A}$ and $\mathrm{B}$ ).

A brain magnetic resonance imaging (MRI) with contrast to rule out infiltrative or compressive causes of the optic nerve edema was within normal limits. The patient had no giant cell arteritis symptoms and no headaches prior to this acute event, and the headaches resolved completely after the LPI. The patient was diagnosed with NAION related to angle closure.
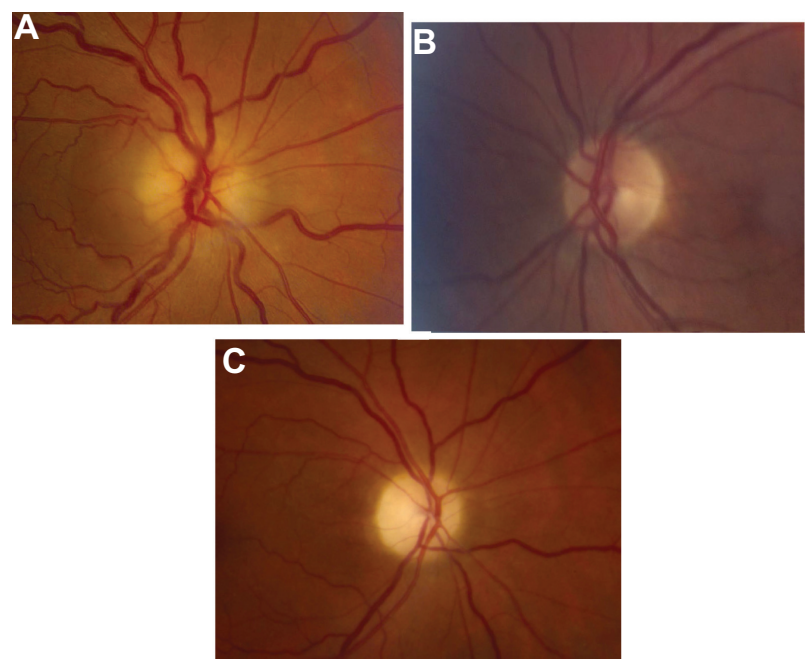

Figure I Fundus photo of the right and left eye.

Notes: (A) The right optic nerve head had diffuse edema with an area of subretinal fluid extending from the temporal border of the optic disc to the nasal macula. (B) The left eye had a cup-to-disc ratio of $<0$.I without any evidence of optic nerve edema. (C) Fundus photo of the right eye at I-month follow-up demonstrates $360^{\circ}$ optic nerve pallor after resolution of the optic nerve edema. The area of subretinal fluid adjacent to the temporal optic disc in the nasal macula has resolved.

The patient was counseled on the importance of stopping use of her antihypertensive medications in the evening and of improved blood pressure and dyslipidemia control. An LPI was performed in her left eye without complications. Two days after presentation, the patient was started on oral prednisone taper $(60 \mathrm{mg}$ prednisone daily for 2 weeks, followed by $50 \mathrm{mg}$ for 5 days and then $40 \mathrm{mg}$ for 5 days, and then cutting down by $5 \mathrm{mg}$ every 3 days to $5 \mathrm{mg}$, followed by $2.5 \mathrm{mg}$ for 3 days and then $1 \mathrm{mg}$ for 3 days) and instructed to follow-up in one month. The decision to use steroids in this patient was based on a retrospective study by Hayreh and Zimmerman, which demonstrated improvement in VA and visual field in NAION patients who presented within two weeks of onset. ${ }^{10} \mathrm{~A}$ larger improvement was seen in patients with poorer presenting VA. ${ }^{10}$

One month later, VA was count fingers at two feet in the right eye and 20/20 in the left. The IOP was 12, right eye, and 14, left eye. A Humphrey visual field of the right eye demonstrated a cecocentral scotoma (Figure 3 ). The optic nerve edema of the right eye resolved and the disc had diffuse atrophy (Figure 1C). The patient was prescribed new polycarbonate lenses and counseled about monocular precautions.

\section{Discussion}

NAION secondary to APAC is a rare clinical entity that can result in severe vision loss. NAION is caused by ischemia to the optic nerve head, mainly from the posterior ciliary artery and its branches. ${ }^{11}$ Blood flow to the optic nerve head is determined by 
A ONH and RNFL OU analysis: optic disc cube 200x200

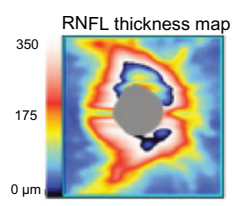

RNFL deviation map

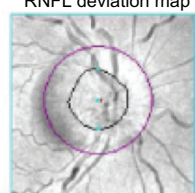

Disc center $(-0.21,0.24) \mathrm{mm}$ extracted horizontal tomogram
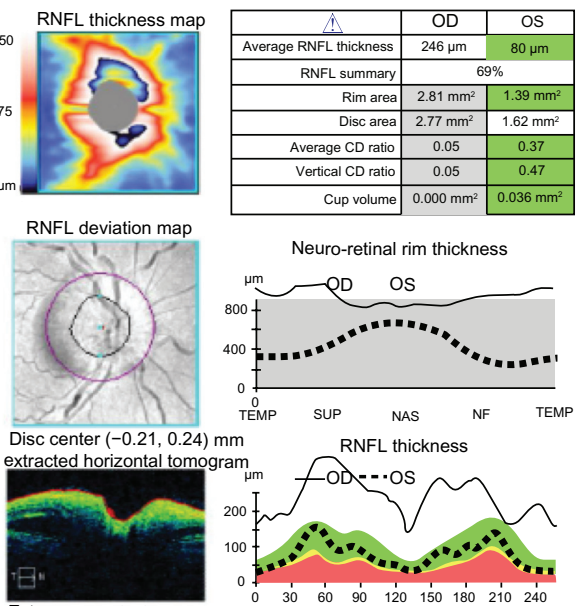

Neuro-retinal rim thickness
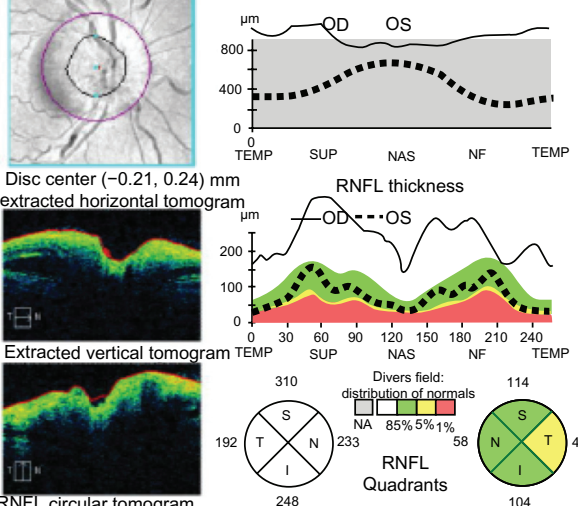

RNFL circular tomogram
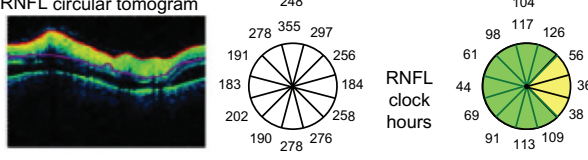

OD OS

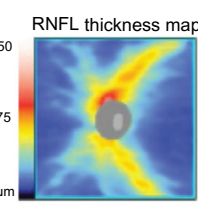

RNFL deviation map

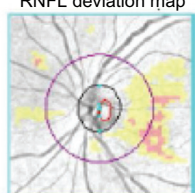

Disc center $(-0.09,-0.03) \mathrm{mm}$ extracted horizontal tomogram

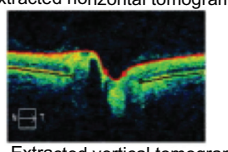

Extracted vertical tomogram

.

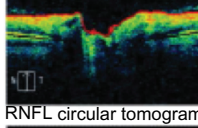

RNFL circular tomogram

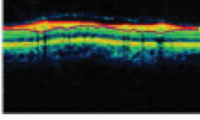

B

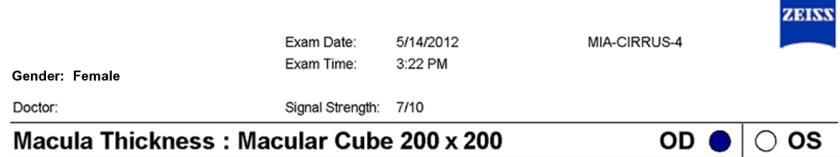

Macula Thickness : Macular Cube $200 \times 200$

OD O OS
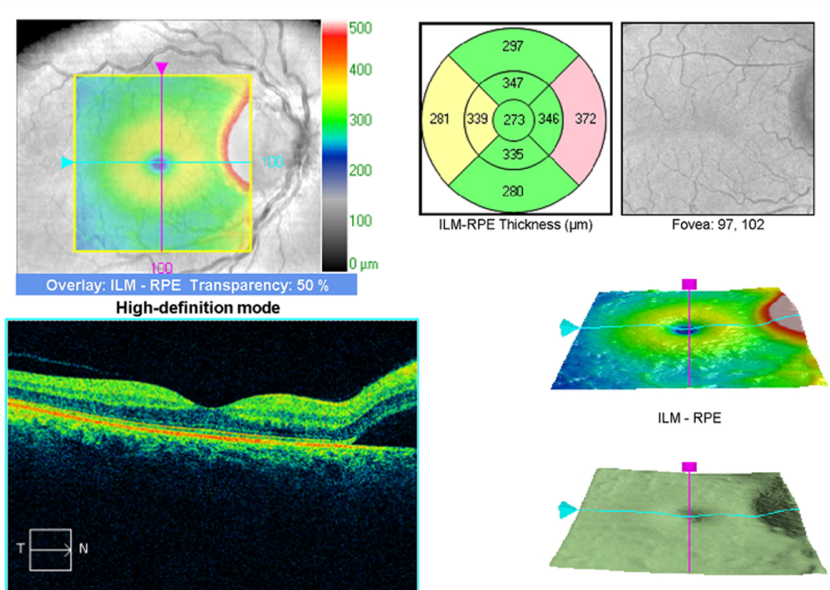

ILM-RPE
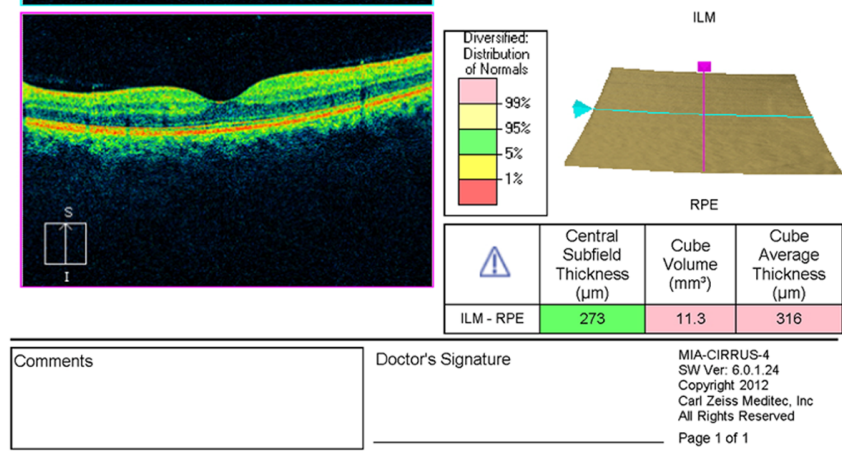

Figure 2 OCT of the optic nerve and macula. (A) Retinal nerve fiber layer analysis demonstrates $360^{\circ}$ optic nerve edema in the right eye and no optic nerve edema in the left. (B) Macula OCT demonstrates a small area of subretinal fluid extending from the temporal portion of the optic disc into the nasal macula in the right eye.

Abbreviations: ONH, optic nerve head; RNFL, retinal nerve fiber layer; OU, both eyes; SUP, superior; NAS, nasal; TEMP, temporal; OD, right eye; OS, left eye; OCT, optical coherence tomography; CD, cup to disc. 


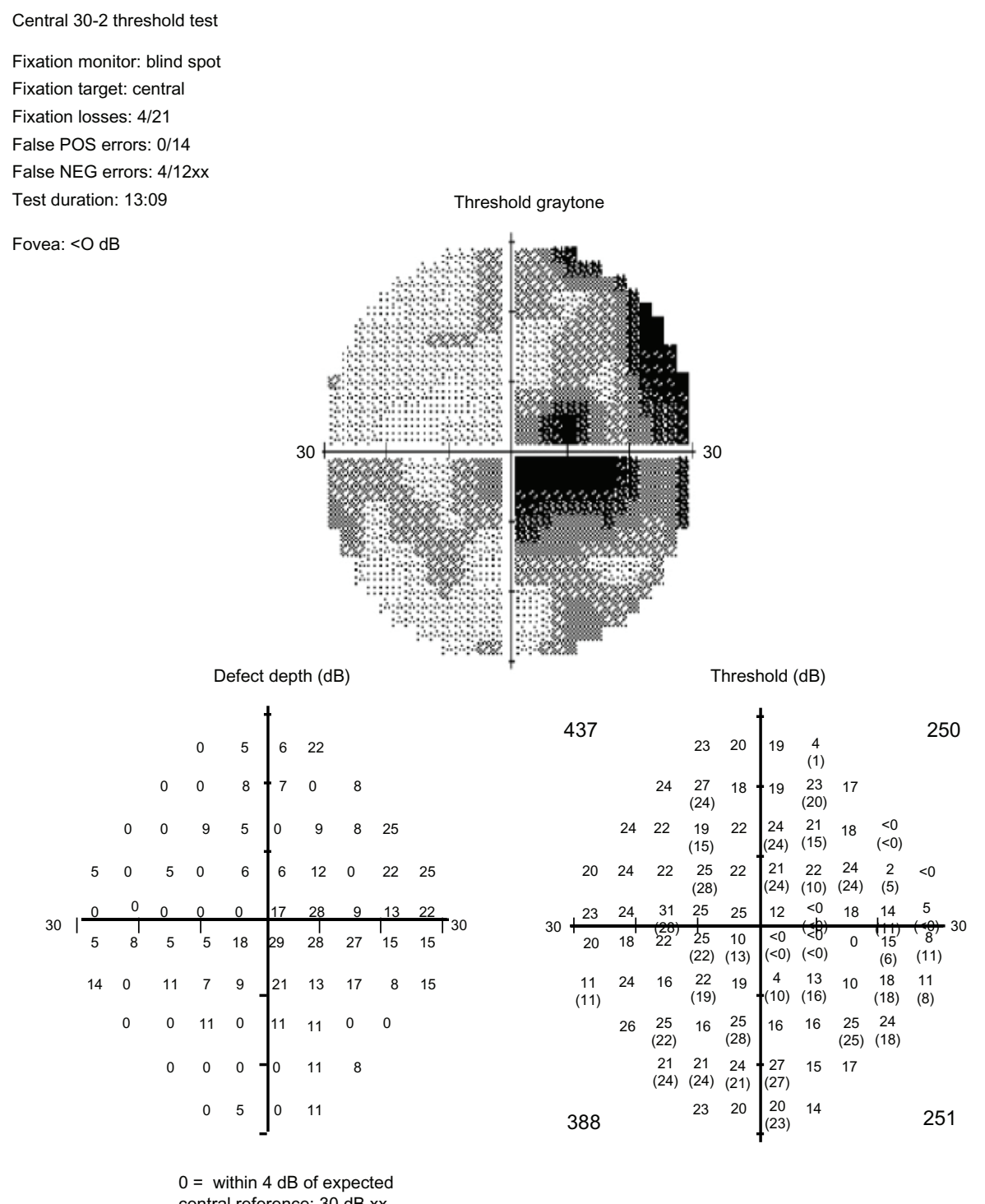

Figure 3 Stimulus $\vee$ 30-2 Humphrey visual field demonstrates a cecocentral scotoma in the right eye.

Abbreviations: POS, positive; NEG, negative; $d B$, decibels.

a ratio of perfusion pressure and resistance to flow. ${ }^{12}$ Resistance to flow is determined by efficiency of autoregulation, vascular integrity, and the rheological properties of blood. ${ }^{12}$ These factors can be impaired in patients with diabetes, hypertension, and atherosclerosis. ${ }^{12}$ Perfusion pressure is determined by the difference in mean arterial pressure (MAP) and IOP. ${ }^{12}$ The MAP is reduced with relative nocturnal hypotension and antihypertensive medications. ${ }^{12}$ High IOPs during phacoemulsification may contribute to the increased incidence of NAION after cataract surgery. ${ }^{13-15}$ Elevated IOP has been identified as a cause of decreased blood flow to the optic nerve head in five cases (six eyes) previously reported by other authors and our case of NAION after APAC (Table 1). ${ }^{5-9}$
Taken together with our case, of all seven eyes with APACassociated NAION, the duration of APAC symptoms ranged from 1 day to 1 month. Five of the seven eyes had NAION at presentation, while the remainder developed NAION one week after presentation for APAC. The IOP at presentation ranged from 40-56 mmHg. Five of seven eyes underwent LPI in the NAION eye and contralateral eye. ${ }^{5-9}$ Slavin and Margulis described one patient who developed an NAION one week after an APAC attack in the left eye and refused an LPI in the right eye. ${ }^{8}$ One month later, the patient had an APAC attack in the right eye and developed a right NAION a week later. ${ }^{8}$ Sequential NAION has not been reported in the other APACassociated NAION cases. ${ }^{5-7,9}$ One possible hypothesis for the 
Table I Summary of the five previously reported patients with NAION-associated APAC (six eyes) and our additional patient

\begin{tabular}{|c|c|c|c|c|c|c|c|c|c|c|}
\hline Paper & Age & Eye & $\begin{array}{l}\text { Symptom } \\
\text { duration }\end{array}$ & $\begin{array}{l}\text { Time to } \\
\text { NAION }\end{array}$ & $\begin{array}{l}\text { Initial } \\
\text { VA }\end{array}$ & IOP & APD & C/D & $\begin{array}{l}\text { Final } \\
\text { VA }\end{array}$ & VF defect \\
\hline $\begin{array}{l}\text { Sonty and } \\
\text { Schwartz, }{ }^{5}\end{array}$ & 66 & OS & $\begin{array}{l}\text { I month, } \\
\text { intermittent }\end{array}$ & Presentation & $20 / 100$ & 55 & NR & NR & $20 / 50$ & Nasal \\
\hline \multirow[t]{2}{*}{$\begin{array}{l}\text { Slavin and } \\
\text { Margulis, }{ }^{8}\end{array}$} & 70 & OD & I day & I week & $20 / 200$ & 56 & NR & 0.1 & $20 / 200$ & $\begin{array}{l}\text { Central scotoma } \\
\text { and inferior }\end{array}$ \\
\hline & & OS & I day & I week & $\mathrm{HM}$ & 50 & NR & 0.1 & $2 / 200$ & $\begin{array}{l}\text { Central scotoma } \\
\text { and inferior }\end{array}$ \\
\hline Yip et al, ${ }^{6}$ & 64 & OS & 5 day & Presentation & $\mathrm{HM}$ & 54 & $Y$ & NR & HM & NR \\
\hline Nahum et al, ${ }^{7}$ & 59 & OS & $N R$ & Presentation & $20 / 30$ & 40 & & Crowded & $20 / 25$ & Superior \\
\hline Choudhari et al, 9 & 59 & OS & I week & Presentation & $20 / 120$ & 46 & Y & NR & $20 / 20$ & Constricted \\
\hline $\begin{array}{l}\text { Kuriyan and Lam, } \\
2013\end{array}$ & 50 & OD & I day & Presentation & $\mathrm{HM}$ & 41 & Y & $<0.1$ & HM & $\begin{array}{l}\text { Cecocentral scotoma, } \\
\text { peripheral constriction }\end{array}$ \\
\hline
\end{tabular}

Abbreviations: OS, left eye; OD, right eye; NAION, non-arteritic ischemic optic neuropathy; APAC, acute primary-angle closure; VA, visual acuity; IOP, intraocular pressure; APD, afferent pupillary defect; C/D, cup to disc ratio; VF, visual field; NR, not reported; HM, hand motion; $Y$, yes.

1 week delay in presentation with NAION after presentation with APAC in this patient is that the initial APAC event may have started the cycle of NAION, but it was not clinically significant for 1 week. Hayreh described the cycle of NAION as ischemia of axons resulting in axoplasmic flow stasis, which in turn cause axoplasmic accumulation and subsequent axonal swelling, which in turn compresses the capillaries, leading to more ischemia. ${ }^{12}$

Including our patient, only two of the seven eyes (29\%) with APAC-associated NAION attained acuity of $20 / 30$ or better, ${ }^{5-9}$ which is worse than the $49 \%$ of NAION patients who attained $20 / 30$ or better in a study by Hayreh et al. ${ }^{16}$ However, the low sample size of APAC-associated NAION patients is a barrier for meaningful comparisons with other NAION patients. It is also possible that the 2 cases of the delayed onset NAION after APAC previously reported may be spontaneous NAION.

Patients with APAC can also develop mild optic nerve edema that is not associated with NAION. ${ }^{17}$ Tsai et al found a statistically significant difference in the retinal nerve fiber layer thickness (RNFL) of the APAC eye and the contralateral eye measured by OCT 1 week after the APAC event. ${ }^{17}$ However, a statistically significant difference was not observed at the 4- and 12-week follow-ups. ${ }^{17}$ These patients can be differentiated from NAION secondary to APAC patients by the lack of subsequent optic nerve atrophy and preserved visual acuity and visual field.

NAION secondary to APAC is a rare but potentially blinding clinical entity. In addition to counseling patients about NAION risk factors (eg, evening antihypertensive medications and control of hypertension, diabetes, and dyslipidemia), patients must be counseled on the importance of performing an LPI in the contralateral eye. In APAC patients with an RAPD, a large amount of optic nerve edema, persistent decreased visual acuity, and a small cup-to-disc ratio in the contralateral eye should raise clinical suspicion for NAION.

\section{Disclosure}

The authors report no conflicts of interest in this work.

\section{References}

1. Klein BE, Klein R, Sponsel WE, et al. Prevalence of glaucoma. The Beaver Dam Eye Study. Ophthalmology. 1992;99(10):1499-1504.

2. Tielsch JM, Katz J, Singh K, et al. A population-based evaluation of glaucoma screening: the Baltimore Eye Survey. Am J Epidemiol. 1991; 134(10):1102-1110.

3. Hattenhauer MG, Leavitt JA, Hodge DO, Grill R, Gray DT. Incidence of nonarteritic anterior ischemic optic neuropathy. Am J Ophthalmol. 1997;123(1):103-107.

4. Johnson LN, Arnold AC. Incidence of nonarteritic and arteritic anterior ischemic optic neuropathy. Population-based study in the state of Missouri and Los Angeles County, California. J Neuroophthalmol. 1994;14(1):38-44.

5. Sonty S, Schwartz B. Vascular accidents in acute angle closure glaucoma. Ophthalmology. 1981;88(3):225-228.

6. Yip LW, Yong VK, Hoh ST, Wong HT. Optical coherence tomography of optic disc swelling in acute primary angle-closure glaucoma. Arch Ophthalmol. 2005;123(4):567-569.

7. Nahum Y, Newman H, Kurtz S, Rachmiel R. Nonarteritic anterior ischemic optic neuropathy in a patient with primary acute angle-closure glaucoma. Can J Ophthalmol. 2008;43(6):723-724.

8. Slavin ML, Margulis M. Anterior ischemic optic neuropathy following acute angle-closure glaucoma. Arch Ophthalmol. 2001;119(8):1215.

9. Choudhari NS, George R, Kankaria V, Sunil GT. Anterior ischemic optic neuropathy precipitated by acute primary-angle closure. Indian J Ophthalmol. 2010;58(5):437-440.

10. Hayreh SS, Zimmerman MB. Non-arteritic anterior ischemic optic neuropathy: role of systemic corticosteroid therapy. Graefes Arch Clin Exp Ophthalmol. 2008;246(7):1029-1046.

11. Hayreh SS. Management of ischemic optic neuropathies. Indian $J$ Ophthalmol. 2011;59(2):123-136.

12. Hayreh SS. Ischemic optic neuropathy. Prog Retin Eye Res. 2009; 28(1):34-62. 
13. Lam BL, Jabaly-Habib H, Al-Sheikh N, et al. Risk of non-arteritic anterior ischaemic optic neuropathy (NAION) after cataract extraction in the fellow eye of patients with prior unilateral NAION. Br J Ophthalmol. 2007;91(5):585-587.

14. McCulley TJ, Lam BL, Feuer WJ. Incidence of nonarteritic anterior ischemic optic neuropathy associated with cataract extraction. Ophthalmology. 2001;108(7):1275-1278.

15. Zhao Y, Li X, Tao A, Wang J, Lu F. Intraocular pressure and calculated diastolic ocular perfusion pressure during three simulated steps of phacoemulsification in vivo. Invest Ophthalmol Vis Sci. 2009;50(6): 2927-2931.
16. Hayreh SS, Zimmerman MB. Nonarteritic anterior ischemic optic neuropathy: natural history of visual outcome. Ophthalmology. 2008; 115(2):298-305.

17. Tsai JC, Lin PW, Teng MC, Lai IC. Longitudinal changes in retinal nerve fiber layer thickness after acute primary angle closure measured with optical coherence tomography. Invest Ophthalmol Vis Sci. 2007; 48(4):1659-1664.

\section{Publish your work in this journal}

Clinical Ophthalmology is an international, peer-reviewed journal covering all subspecialties within ophthalmology. Key topics include: Optometry; Visual science; Pharmacology and drug therapy in eye diseases; Basic Sciences; Primary and Secondary eye care; Patient Safety and Quality of Care Improvements. This journal is indexed on

\section{Dovepress}

PubMed Central and CAS, and is the official journal of The Society of Clinical Ophthalmology (SCO). The manuscript management system is completely online and includes a very quick and fair peer-review system, which is all easy to use. Visit http://www.dovepress.com/ testimonials.php to read real quotes from published authors. 